\title{
Magnetic Resonance Imaging Localization of the Vertebral Level of Termination of the Spinal Cord in Adults in Port Harcourt, Rivers State, Nigeria
}

\author{
Mbaba AN ${ }^{1}$, Ogolodom MP2*, Abam R ${ }^{1}$, ljeruh OY ${ }^{1}$, Okpaleke MS ${ }^{3}$, Maduka BU ${ }^{4}$, Iwuagwu OC \\ ${ }^{1}$ Department of Radiology, Rivers State University Teaching Hospital, Port Harcourt Rivers State, Nigeria \\ ${ }^{2}$ Rivers State Hospitals Management Board, Port Harcourt Rivers State, Nigeria \\ ${ }^{3}$ Department of Radiography and Radiological Sciences Nnamdi Azikiwe University, Nnewi Campus, Anambra State, Nigeria \\ ${ }^{4}$ Department of Medical Radiography and Radiological Sciences, University of Nigeria Enugu Campus, Nigeria \\ ${ }^{5}$ Radiology Department, Federal Medical Centre Owerri, Imo State, Nigeria
}

*Corresponding author: Michael Promise Ogolodom, Rivers State Hospitals Management Board, Port Harcourt Rivers State, Nigeria, Tel: +23408039697393; E-mail: mpos2007@yahoo.com

Received date: March 16, 2020; Accepted date: April 01, 2019; Published date: April 07, 2020

Citation: Mbaba AN, Ogolodom MP, Abam R, ljeruh OY, Okpaleke MS, et al. (2020) Magnetic Resonance Imaging Localization of the Vertebral Level of Termination of the Spinal Cord in Adults in Port Harcourt, Rivers State, Nigeria. Arch Med Vol: 12 Iss: 2:5

Copyright: (2020 Mbaba AN, et al. This is an open-access article distributed under the terms of the Creative Commons Attribution License, which permits unrestricted use, distribution, and reproduction in any medium, provided the original author and source are credited.

\section{Abstract}

Background: A wide range of variation in the termination of the spinal cord in normal adult population has been observed. Studies abound in foreign literature on the termination of the spinal cord but there is dearth of data concerning this subject in our environment. A good knowledge of the normal level of termination of the conus medullaris in our setting is imperative in every day medical practice.

Aim of the study: To determine the vertebral levels of termination of the spinal cord in living adult population in Port Harcourt Metropolis, Rivers State, Nigeria using MRI and to compare findings with previous similar studies.

Materials and Methods: A retrospective cross-sectional design was adopted in this study and was conducted in a single radio-diagnostic center with MRI scanner in Port Harcourt metropolis, Rivers State, Nigeria. Ethical approval was obtained from the Research Review Committee Board of the study center and the retrieved data were treated with utmost confidentiality and used for the purpose of this study only. Both T1W and T2W mid sagittal, spin-echo MR images were analyzed. The terminations of the conus medullaris were identified on sagittal images and were defined as the most distal point of the cord that could be visualized on the sagittal image. A line perpendicular to the long axis of the cord was drawn and extended to the adjacent vertebra. This location was recorded in relation to the upper, middle, or lower third of the adjacent vertebral body or the adjacent intervertebral disc. The obtained data were analyzed using SPSS version 22.

\begin{abstract}
Results: Out of the 177 study population, greater numbers of the spinal cords terminated at middle third of L1 74 (males: 35 (36.47\%) and females: 39 (48.75\%)) as highest and the least terminated at the L3U, which is 1 (male: $1(1.04 \%)$. Maximum numbers of the cases were within the age group 46-55 years old, 54 (Middle third of $L 1=29(16.38 \%$, upper third of $L 2=6(3.39 \%)$ and lower third of $L 2=4(2.26 \%)$ and the least were within the age group 15-25 years, which is 6 (middle third of $L 1=3$ (1.69\%), middle third of $L 2=I(1.04 \%)$ and $T 12 / L 1$ $\operatorname{disc}=1(1.04 \%))$.
\end{abstract}

Conclusion: The average level of termination of the spinal cord in our study is at the middle third of L1 vertebral body. No gender difference in spinal cord termination. It is hoped that the finding of this study will serve as a useful guide for medical practitioners in our setting.

Keywords: Conus medularis; MRI; Termination

\section{Introduction}

The spinal cord is an important structure in humans and its caudal end is referred to as the Conus Medullaris (CM). The termination of the conus medullaris with respect to the vertebral level in normal population has been widely studied [1-5] and variations in the termination of the spinal cord have also been documented [4]. Previous studies reported that the conus medullaris most commonly terminates at $\mathrm{L} 1 / 2$ intervertebral level in both children and adults $[2,3,6]$. However, it has been observed that termination of the spinal cord varies from mid-T11 to mid-L3 vertebral body levels and the average termination varies from study to study $[2,3,6]$.

The position of the conus medularis is defined as the most distal point of the cord and the factors that may affect the 
conus position after attaining its final level remains largely unidentified [1]. In the past, it was stated that the female cords and those of negroes tend to be slightly longer on average than those of white males $[7,8]$. Nevertheless, recent studies revealed that there is no remarkable difference in spinal cord termination in both males and females and in the different age groups except neonates/infants less than one year old $[9,10]$. The level of termination of the conus medullaris has been studied, mostly in cadavers and living subjects using myelography. However, MRI has made possible the study of the level of termination of the conus medullaris in living humans.

Magnetic Resonance Imaging (MRI) is a good imaging modality, which gives near accurate information on the various body structures. The level of termination of $\mathrm{CM}$ can be accurately defined on majority of mid sagittal T1 weighted Lumbosacral MRI studies [11].

Studies abound in foreign literatures on the determination of the termination of the spinal cord either from cadaveric studies or studies in the living humans. However, there is dearth of data concerning this subject in our environment. A good knowledge of the level of termination of the conus medullaris in normal adult population in our setting is imperative for clinicians while performing diagnostic or therapeutic lumbar puncture. This study is designed to evaluate the level of termination of the spinal cord in living normal adult population in Port Harcourt Metropolis, Rivers State, Nigeria and also compare findings with similar previous studies.

\section{Materials and Methods}

A retrospective cross-sectional design was adopted in this study and was conducted in a single radio-diagnostic center with MRI scanner in Port Harcourt metropolis, Rivers State, Nigeria. Ethical approval was obtained from the Research Review Committee Board of the study center and the retrieved data were treated with utmost confidentiality and used for the purpose of this study only. A total of 177 radiological images of patients who underwent lumbosacral MRI scan in the selected study center with the view to determine the various causes of low back pain were studied. All the images used in this study were acquired on 0.35 Tesla General Electric medical system MRI machine and were selected based on our predetermined inclusion criteria. Both T1W and T2W mid sagittal, spin-echo $M R$ images were analyzed. The terminations of the conus medullaris were identified on sagittal images and were defined as the most distal point of the cord that could be visualized on the sagittal image. A line perpendicular to the long axis of the cord was drawn and extended to the adjacent vertebra (Figure 1). This location was recorded in relation to the upper, middle, or lower third of the adjacent vertebral body or the adjacent intervertebral disc (Figure 2) according to Saifuddin et al. [5].

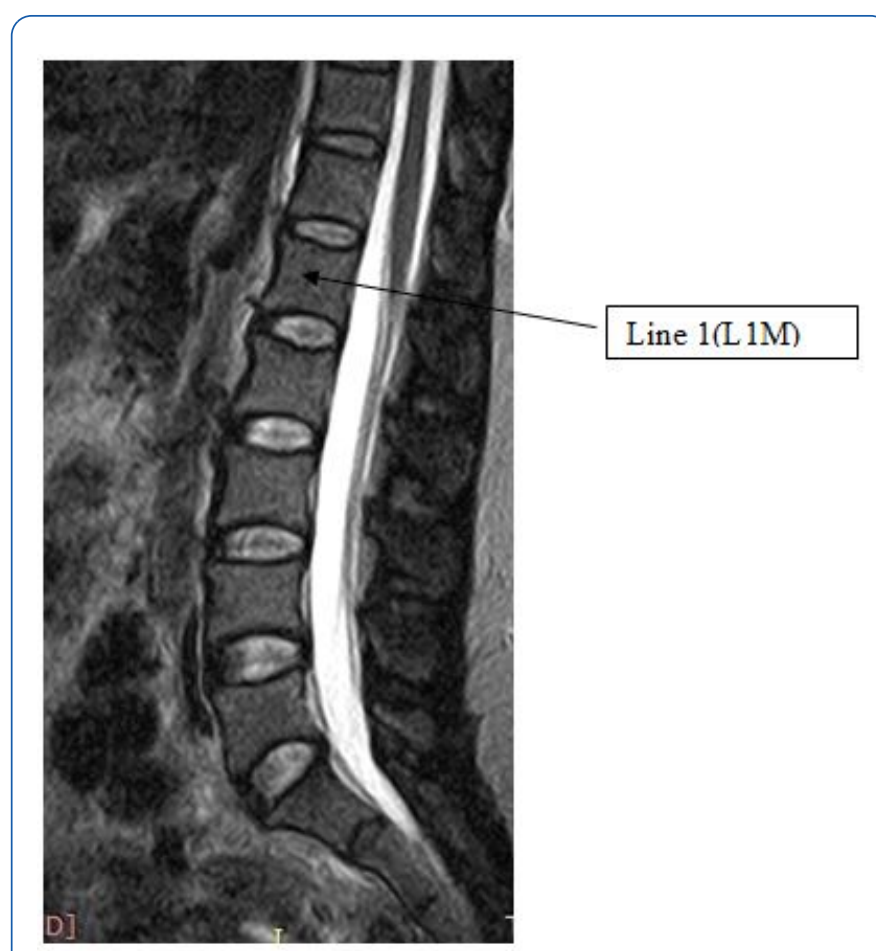

Figure 1 Sagittal T2W image showing a line (line 1) drawn perpendicular to the long axis of the cord and extended to the adjacent vertebra to indicate the level of termination of the conus medullaris.

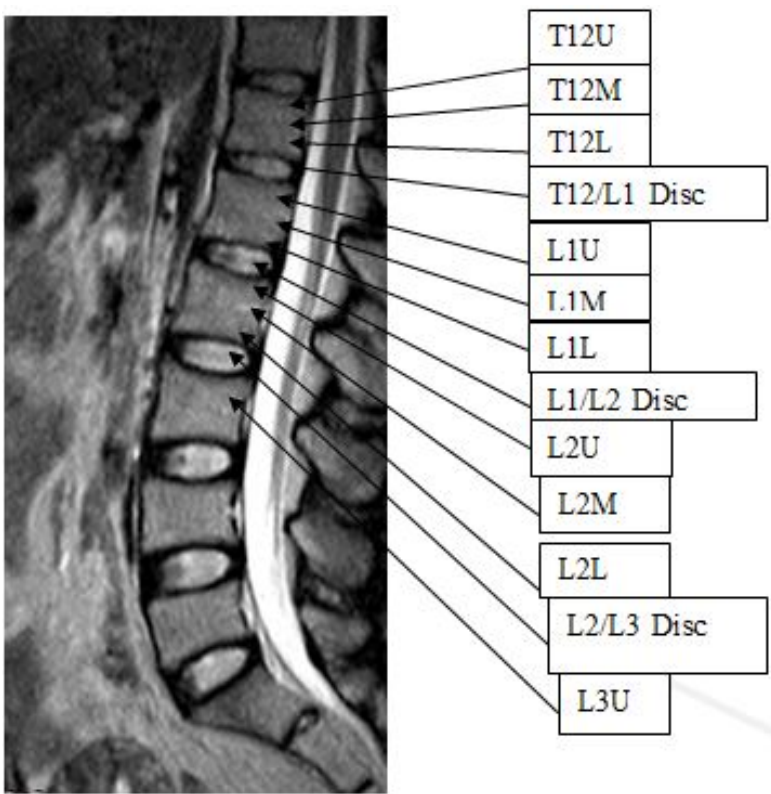

Figure 2 Sagittal T2W image showing lines drawn in relation to the upper, middle, or lower third of the adjacent vertebral body or the adjacent intervertebral disc.

\section{Result}

The study population consisted of $92(51.98 \%)$ men and 85 $(48.02 \%)$ women with a mean age of 39.56 years. The 
distribution of the spinal cord termination levels in living normal adult population were measured to range from T12M to L3. The evaluation of the termination levels was done according to gender and age. Of the 177 study population, greater numbers of the spinal cords terminated at middle third of L1, which is 74 (males: 35 (36.47\%) and females: 39 $(48.75 \%))$ as highest, followed by those that terminated at upper third of L2, 21 (males: 13(13.54) and females: 8(10\%) and the least terminated at the $L 3$, which is 1 (male: $1(1.04 \%)$ (Figure 3).

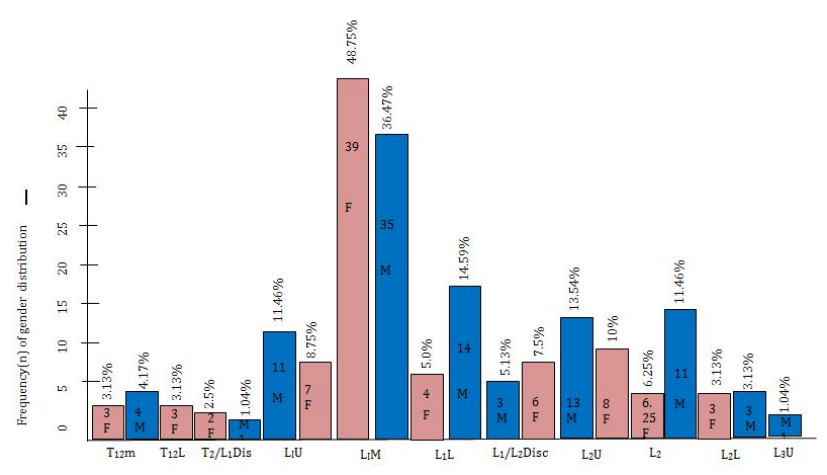

Figure 3 Termination of the spinal cords levels.

With regards to age distributions of the termination of the spinal cords, maximum numbers of the cases were within the age group 46-55 years old, 54 (Middle third of $L 1=29$ (16.38\%, upper third of $L 2=6(3.39 \%)$ and lower third of $L 2=4(2.26 \%)$, followed by the age group 36-45 years old, 37 (middle third of $\mathrm{L} 1=20(11.69 \%)$, middle third of $\mathrm{L} 2=1(1.04 \%)$ and lower third of $L 2=1(1.04 \%)$ and the least were within the age group 15-25 years, which is 6 (middle third of $L 1=3(1.69 \%)$, middle third of $\mathrm{L} 2=\mathrm{I}(1.04 \%)$ and T12/L1 disc=1(1.04\%]) (Table 1).

Table 1 Frequency distribution of spinal cord termination among the subject age groups.

\begin{tabular}{|c|c|c|c|c|c|c|c|c|}
\hline \multirow{2}{*}{$\begin{array}{c}\text { Vertebr } \\
\text { al } \\
\text { Levels }\end{array}$} & \multicolumn{8}{|c|}{ Age Groups (Years) } \\
\hline & $\begin{array}{c}15-2 \\
05\end{array}$ & $\begin{array}{c}26- \\
35\end{array}$ & $\begin{array}{c}36- \\
45\end{array}$ & $\begin{array}{c}46-5 \\
5\end{array}$ & $\begin{array}{l}56- \\
65\end{array}$ & $\begin{array}{c}66- \\
75\end{array}$ & $\begin{array}{c}76- \\
85\end{array}$ & $\begin{array}{l}\text { To } \\
\text { tal }\end{array}$ \\
\hline $\mathrm{T} 12 \mathrm{M}$ & & & & & & 5 & 2 & 7 \\
\hline $\mathrm{T} 12 \mathrm{~L}$ & & 1 & & & & 1 & 1 & 3 \\
\hline $\begin{array}{l}\text { T12/ } \\
\text { L1DIS } \\
\text { C }\end{array}$ & 1 & 1 & & & & 1 & & 3 \\
\hline L1U & & & 6 & 9 & 2 & 1 & & 18 \\
\hline L1M & 3 & 6 & 20 & 29 & 8 & 5 & 3 & 74 \\
\hline L1L & & 2 & & 3 & 9 & 4 & - & 18 \\
\hline $\begin{array}{l}\text { L1/ } \\
\text { L2DIS } \\
\quad C\end{array}$ & 1 & - & - & 3 & 4 & 2 & - & 10 \\
\hline L2U & & 3 & 9 & 6 & 2 & 1 & & 21 \\
\hline L2M & 1 & 1 & 1 & 4 & 7 & 1 & 1 & 16 \\
\hline
\end{tabular}

\begin{tabular}{|c|r|r|r|r|r|r|r|r|}
\hline L2L & & 1 & 1 & - & & 4 & & 6 \\
\hline L3U & & - & & - & & & 1 & 1 \\
\hline Total & $\mathbf{6}$ & $\mathbf{1 5}$ & $\mathbf{3 7}$ & $\mathbf{5 4}$ & $\mathbf{3 2}$ & $\mathbf{2 5}$ & $\mathbf{8}$ & \begin{tabular}{c}
$\mathbf{7}$ \\
\hline
\end{tabular} \\
\hline
\end{tabular}

\section{Discussion}

Prior to the era of modern imaging modalities such as MRI, scientists evaluated the termination levels of spinal cord and dural sac by dissection of cadavers and it was generally agreed that the conus medullaris terminates in the lower third of $L 1$ vertebra $[4,12,13]$. With the introduction of $\mathrm{MRI}$, researchers had documented that there is wide range of termination of spinal cord in live healthy subjects [12].

In our study, the male population was highest when compared with their female counterparts. This finding is similar to the finding of the study conducted by Sharma et al. [14]. Sharma et al. included $50.79 \%$ males and $49.21 \%$ females. This finding is contrary to the findings of the studies carried out by Karabulut et al. [15], Binokay et al. [16] and Saifuddin et al. [5]. Karabulut et al. study, they studied data which comprised of 607 women and 314 men. Binokay et al. [16] study, reported higher female population, which was 400 out of 682 sample size. The differences in our findings could be ascribed to the different sample sizes studied and the geographical variations. Saifuddin et al. [5] study group consisted of 231 men and 273 women.

Majority of the cases included in this study, were within the age group of 46-55 years with varying cord termination distribution. There is no difference in the cord termination in males and females.

In our study we found that the spinal cord was located between middle third of T12 and L3 vertebral bodies. This finding corroborates with the findings of studies conducted by Saifuddin et al. [5], Moussallem et al. [11], Moore and Persaud [17], Grewal and Tarpey [18]. Saifuddin et al. [5] study, which was conducted to evaluate the variation of position of the conus medullaris in 504 adult population that underwent MRI scan of lumbosacral spine, found that conus medullaris was located between middle third of T12 and upper third of L3 vertebral bodies. Grewal and Tarpey [18] study, which was carried out to assess the damage to the conus medullaris from spinal anesthesia, revealed that the conus position varied from middle third of T12 to upper third of L3. Moussallem et al. [11] study, conducted to determine the relationship of the lumbar lordosis angle to the level of termination of the conus medullaris and thecal sac, found that the position of the CM range between middle third of T12 and the upper third of L3. Also, Moore and Persud [17] reported that the mean conus position range was between the middle third of T12 and the upper third of L3. The finding of this current study is not in agreement with findings of similar studies by Thomson [19], McCotter [20], Karabulut et al. [15], Rahmani et al. [21]. Thomson [19] study found that the range for the cord termination was between the lower third of T12 and the upper third of L3 vertebral bodies. Similarly McCotter [20] reported 
conus termination between the upper T12 and L2-L3discs. The discrepancies in our findings could be ascribed to the different sample sizes, nature of the studies and the geographical variations of the various studies.

In our study, we found that the majority of the cases had the cord terminated at the middle third of L1. This finding is consistent with the findings of the studies conducted by Malas et al. [22], Demirywrek et al. [4] and Moon et al. [23]. Malas et al. [22] study, which was carried out to investigate the conus medullaris termination level during the period of fetal development to adulthood, revealed termination of the conus at $\mathrm{L} 162.5 \%$ and $21.8 \%$ between $\mathrm{L} 1$ and $\mathrm{L} 2$. Demiryurek et al. [4], also reported the termination of conus at L1 with the highest percentage $44.4 \%$. Moon et al. [23] in their study, designed to determine the conus medullaris in a Korean population using $\mathrm{MRI}$, reported that the majority of the case had their conus termination at L1 (52.4\%).

The termination of conus medullaris at L1 has been ascribed to the non-uniform growth of the conus with the bony spinal column during the embryonic period $[3,4,6,24]$. The slight differences in our findings could be attributed to the different sample size studied.

Our finding is in contrast with the findings of other related studies conducted by Gatonga et al. [25], Karabulut et al. [15], Thomson, [19], McCotter [20]. Gatonga et al. study, which was conducted to evaluate the spinal cord termination in adult Africans and also determine its relationship with the intercristal line and the transumbilical plane, reported that the upper third of L2 had the highest percentage of cord terminations (51.9\%). Karabulut et al. [15], reported L1-L2 as the highest point of cord termination (272, 29.5\%). Thomson [19], found the conus termination at L2 in $43 \%$ in men and $27 \%$ in women. McCotter [20] found that $77 \%$ of the men had their cord termination between upper third of L1 and the upper third of L2. According to McCotter [20], lower termination for women was noticed and the lowest level of the termination was the lower third of L3. Several researchers noticed that the older patients with osteoporosis or age related vertebral abnormalities normally have decrease in height of the vertebral body and the segmental position of the conus could be relatively lower $[26,27]$. According to Gatonga et al. [25], the spinal cord, which terminates at or below the upper third of L2, should informed adequate care when carrying out lumbar punctures and spinal epidural anesthesia among Africans. According to Gatontga et al, intercristals line and transumbilical plane are safe sites to use in identifying the conus medullaris. The different sample size, nature of the studies which centered on the study objectives contributed greatly to the discrepancies identified in our findings.

\section{Conclusion}

The average level of termination of the spinal cord in our study is at the middle third of L1 vertebral body. No difference was observed in the termination of the spinal cord between males and females and in the different age ranges. It is hoped that the findings of this study will serve as a useful guide for medical practitioners in our setting.

\section{Conflict of Interest}

None-declared

\section{References}

1. Qu Z, Qian B, Qui Y, Zhang Y, Hu Jhu Z (2017) Does the position of conus medullaris change with increased thoracolumbar kyphosis in ankylosing spondylitis patients. Medicine (Baltimore) 96: e5963.

2. Kesler H, Dias MS, Kalapos P (2007) Termination of the normal conus medullaris in children: a whole-spine magnetic resonance imaging study. Neurosurg Focus 23: E7.

3. Soleiman J, Demaerel P, Rocher S, Maes F, Marchal G (2005) Magnetic resonance imaging study of the level of termination of the conus medullaris and the thecal sac: influence of age and gender. Spine 30: 1875-1880.

4. Demiryurek $D$, Aydingoz U, Aksit MD, Yener N, ÖGeyik $P$ (2002) MR imaging determination of the normal level of conus medullaris. Clin Imaging 26: 375.

5. Saifuddin A, Burnett SJ, White J (1998) The variation of position of the conusmedullaris in an adult population. A magnetic resonance imaging study. Spine 23:1452-1456.

6. Wilson DA, Prince JR, John CA (1989) MR imaging determination of the location of the normal conusmedullaris throughout childhood. AJR Am J Roentgenol 152: 1029-1032.

7. Needles JH (1935) The caudal level of termination of the spinal cord in American whites and American negroes. Anat Rec 63: 417-424.

8. Barson AJ (1970) The vertebral level of termination of the spinal cord during normal and abnormal development. J Anat 106: 489-497.

9. Khasawneh RR (2019) Influence of age, sex, height and lumber stenosis on the position of the conusmedullaris in adults. Int J Morphol 37: 867-871.

10. Van Schoor AN, Bosman MC, Bosenberg AT (2015) Descriptive study of the differences in the level of the conusmedullaris in four different age groups. Clin Anat 28: 638-644.

11. Moussallem CD, El Masri H, El-Yahchouchi C, Abou Fakher F, Ibrahim A (2014) Relationship of the lumbar lordosis angle to the level of termination of the Conus Medullaris and thecal sac. Anat Res Int 2014: 351769.

12. Preeti, Charturvedi M (2013) Level of Termination of Spinal Cord (Conus Medullaris). Int J Sc Res 5: 2319-7064.

13. Boonpirak N, Apinhasmit W (1994) Length and caudal level of termination of spinal cord in thai adults. Acta Anat 149: 74-78.

14. Sharma BK, Dey R, Kar S, Singh VK (2017) A magnetic resonance imaging study of the variations of position of conus medullaris and thecal sac in the adult population in Sikkim. Indian J Clin Anat and physic 4: 8-10.

15. Karabulut O, Akay H, Karabulut Z, Özevren H, Saka G, et al. (2016) Conus Medullaris Position in an Adult Population: Analysis of Magnetic Resonance Imaging. Int J Morphol 34: 1352-1356. 
16. Binokay MD, Akgul E, Bicakci $K$, Soyupak $S$, Aksungur $E$, et al. (2006) Determining the Level of the Dural Sac Tip: Magnetic Resonance Imaging in an Adult Population. Acta Radiologica, 47: 397-400.

17. Moore KL, Persaud TVN (1998) The Developing Human. Clinically Oriented Embryology. 6th edn, Philadelphia, Saunders. Pp: 458-460.

18. Grewal BS, Tarpey J (2001) Damage to the Conus Medullaris following spinal anaesthesia: 3. Anaesthesia 56: 812-814.

19. Thomson A (1894) Fifth Annual Report of the Committee of Collective Investigation of the Anatomical Society of Great Britain and Ireland for the Year 1893-94. J Anat Physiol 29: 35-60.

20. McCotter RE (1916) Regarding the length and extent of the human medulla spinalis. Anat Rec 10: 559-564.

21. Rahmani M, Samghabadi MAS, Bozorg SMV (2009) Magnetic Resonance Imaging based Determination of Conus Medullaris Position in Adults. Res J Biol Sci 4: 157-159.
22. Malas MA, Salbacak A, Büyükmumcu $M$, Seker $M$, Köylüoglu $B$, et al. (2001) An investigation of the Conus Medullaris termination level during the period of fetal development to adulthood. Kaibogaku Zasshi 76:453-459.

23. Moon M, Jeong J, Kim S, Kim M, Choi W (2019) Magnetic Resonance Imaging Observations of the Conus Medullaris in a Korean Population. Asian Spine J 13: 313-317.

24. Wolf S, Schneble F, Troger J (1992) The conus medullaris: time of ascendence to normal level. Pediatr Radiol 22: 590-592.

25. Gatonga P, Ogeng'o JA, Awori KO (2010) Spinal cord termination in adult Africans: relationship with intercristal line and the transumbilical plane. Clin Anat 23: 563-565.

26. Diacinti D, Acca M, D’Erasmo E, Tomei E, Mazzuoli GF (1995) Aging changes in vertebral morphometry. Calcif Tissue Int 57: 426-429.

27. Pluijm S M, Tromp AM, Smit JH, Deeg DJ, Lips $P$ (2000) Consequences of vertebral deformities in older men and women. J Bone Miner Res 15: 1564-172. 